\title{
Melt processing of polypropylene/clay nanocomposites modified with maleated polypropylene compatibilizers
}

\author{
Yeh Wang ${ }^{\mathrm{a}}$, Feng-B. Chen ${ }^{\mathrm{a}}$, Yann-C. Li ${ }^{\mathrm{b}, *}$, Kai-C. Wu \\ ${ }^{a}$ Department of Chemical Engineering, Tunghai University, Taichung 407, Taiwan, ROC \\ ${ }^{\mathrm{b}}$ Department of Applied Chemistry, National Chiao Tung University, Hsinchu 300, Taiwan, ROC
}

\begin{abstract}
Maleic anhydride-grafted polypropylene (PPgMA) and organically modified clay composites were prepared in a plasticorder. PPgMAs, including PB3150, PB3200, PB3000, and E43, with a wide range of MA content and molecular weight were used. The structure was investigated with X-ray diffraction (XRD) and transmission electron microscopy (TEM). PPgMA compatibilizers gave rise to similar degree of dispersion beyond the weight ratio of 3 to 1 with the exception of E43, which had the highest MA content and the lowest molecular weight. It was found that thermal instability and high melt index were responsible for ineffective modification by E43. Furthermore, PPgMA with low melting point and high melt index was compounded at low equilibrium temperature in order to maintain a certain level of torque. We then modified polypropylene/organoclay nanocomposites with different levels of PPgMA compatibilizers on a twin-screw extruder. The PP/E43/clay system, as shown through XRD patterns and TEM observation, yielded the poorest clay dispersion among the compatibilizers under investigation. The relative complex viscosity curves also revealed a systematic trend with the extent of exfoliation and showed promise for quantifying the hybrid structure of the nanocomposites. Mechanical properties and thermal stability were determined by dynamical mechanical analysis and thermogravimetric analysis, respectively. Though PPgMA with lower molecular weight and higher MA content could lead to good clay dispersion in PP/clay composites, it caused the deterioration in both mechanical and thermal properties of $\mathrm{PP} / \mathrm{PPgMA} /$ clay composites.

(C) 2003 Elsevier Ltd. All rights reserved.
\end{abstract}

Keywords: Nanocomposite; Compatibilizer; Organoclay; Polypropylene

\section{Introduction}

Since the mass production of isotactic polypropylene after the development of 'Ziegler-type' catalysts, commercial exploitation has been very rapid. Such exploitation are due to polypropylene's attractive characters of low cost, low weight, heat distortion temperature above $100{ }^{\circ} \mathrm{C}$, and extraordinary versatility in terms of properties, applications and recycling. The consumption growth rates have been high, with the material becoming widely used in various industrial areas for fibers, films and injection molding articles. Further modification of polypropylene by adding fillers, reinforcements, or blends of special monomers or elastomers can render it more flexible with a variety of other properties, and its competitiveness in engineering resin applications has greatly improved. The addition of nanoscopic fillers of high anisotropy in polymer matrices is therefore of great interest in the polymer industry [1,2]. This interest stems from the fact that when these nanoscopic

\footnotetext{
* Corresponding author.
}

fillers are used instead of a conventional reinforcing, the composite materials exhibit a wide range of enhanced performance, such as mechanical, thermal and gas barrier properties, at a relatively small loading [3-5]. The enhanced reinforcement is a consequence of the much greater surface to volume ratio of these high aspect ratio fillers.

Among various kinds of natural and synthetic clays, the most common nanoscopic filler is derived from montmorillonite (MMT) clay, which is found naturally in a layered silicate structure with a high surface area, about $750 \mathrm{~m}^{2} / \mathrm{g}$. The clay exists in a tactoid structure of 20-25 layers, which translates into an aspect ratio of about 10. Exchanging the cations in between the silicate layers with the bulkier and more organophilic cations, such as a long chain alkylammonium ion, alters the clay structure, which becomes known as organoclay. This cation expands the layer or basal spacing; and the increased spacing makes it possible for the clay layers to be intercalated and exfoliated. The exfoliated clay is the desired material due to the fact that exfoliation creates individual clay platelets, which are of the order of 
$1 \mathrm{~nm}$ in thickness and the aspect ratio is of the order of 100 . Note that it is very common in these systems to be made up of partially exfoliated clay in a combination or a hybrid structure, where only part of the clay exists in the intercalated state and the other parts exist in the exfoliated state.

Although anisotropic nanofillers were found to afford attractive combinations of stiffness and toughness, the dispersion problems due to strong particle interactions of nanofillers have limited their application. Different routes to form polymer/organoclay nanocomposites have been reviewed in the literature [4-9], and a number of paths leading to the dispersion of nanofillers have been proposed for preparing nanocomposites. However, melt intercalation have become the two dominant ways of preparing polymer/ clay nanocomposites due to their cost effectiveness. Melt intercalation involves the mixing of clay with molten polymer matrix. The layer separation, especially exfoliation, depends on the establishment of favorable interactions between the polymer and the clay surface and the subsequent system energy reduction. Examples can be found for polystyrene [10,12-14], polyethylene oxide [11], and nylon [15-17]. More recently direct melt intercalation is being recognized as a promising approach because of its ease by employing conventional polymer mixing or extrusion processes and its environmental benignancy.

Considering melt delamination or exfoliation of organoclay, two-stage mechanism has been proposed $[12,13,17]$. During the first stage, polymer melt intercalates into the expanded clay galleries, and polymer chains need to be transported from the bulk melt into silicate interlayers. They then enter the clay galleries, and push the end of the platelets apart. This pathway does not require high shear but involves diffusion of polymer from the bulk into the clay galleries. The major driving force is either physical or chemical affinity of the polymer for the organoclay surface, and the enthalpy of mixing could be rendered favorable by maximizing the driving force. This is relevant to polymers with polar groups compatible with the polar hydroxyl groups on silicate clay layers. At the second stage, the clay tactoids are exfoliated under shear, stacks of clay platelets are decreased in height by sliding platelets apart from each other, and the contact area between resin matrix and clay platelets is increased. High shear intensity would help the formation of polymer/clay hybrid by breaking up clay particles and increasing sample uniformity. The process is thus facilitated by both residence time and screw configuration in the extruder.

For nonpolar polymers like PP, unless the surface of organoclay is further treated with compatibilizers, applying high shear intensity during melt processing does not cause the clay tactoids to delaminate. Efforts have been made to improve the mixing of clay in PP by using functional oligomers as compatibilizers [18-24] by grafting a polar component such as maleic anhydride to the nonpolar polymer backbone. This produces a functionalized polymer that is compatible with the clay and also miscible with the bulk polymer matrix. Exfoliated and intercalated structures were observed in the modified PP/organoclay composites. In short, the addition of the compatibilizers creates more favorable polymer-clay interactions leading to exfoliation of the clay layers.

Chemical properties of maleated polypropylene that influence their effectiveness as compatibilizers for PP/organoclay nanocomposites are: (1) molecular weight and (2) MA content that relate to the amount of functionality present in the compatibilizer. Several studies concerning the effect of compatibilizers on the clay dispersion via melt process have been reported, and the molecular properties of the compatibilizers and their loadings are summarized in Table 1. The effect of MA content on the clay dispersion has been studied extensively, but the results are somewhat inconsistent. High MA content generally enhances the melt intercalation of PP oligomers into clay layers, however, it may lead to immiscibility with the PP matrix [19] and harm the mechanical properties of the composites. But some authors still found that high MA content (at 4.2\%) improved the mechanical strength better than the low MA content (2.9\%) under the same composition [23]. Since mechanical properties are also affected by the composite composition,

Table 1

Summary of physical properties of compatibilizers and their loadings from the literature

\begin{tabular}{|c|c|c|c|c|c|c|}
\hline Trade name & Molecular wt $\left(M_{\mathrm{w}}\right)$ & Acid value (mg KOH/g) & MA content (wt\%) & PPgMA/clay (wt/wt) & Supplier & References \\
\hline PPMA-1010 & 30,000 & 52 & - & $3 / 1,1 / 1$ and $1 / 3$ & Sanyo & {$[20]$} \\
\hline PPMA-110TS & 12,000 & 7 & & & & \\
\hline $\mathrm{PPOH}$ & 20,000 & 54 (OH value) & & & & \\
\hline PPMA-1010 & 30,000 & 52 & - & $3 / 1$ & Sanyo & [19] \\
\hline PPMA-1001 & 40,000 & 26 & & & & \\
\hline PPMA-1010 & 30,000 & 52 & - & $3 / 1,2 / 1$ and $1 / 1$ & Sanyo & {$[21]$} \\
\hline Hostaprime HC5 & 32,000 & - & $4.2 \%$ & $4 / 1$ and $2 / 1$ & Hoechst & {$[23]$} \\
\hline \multirow[t]{2}{*}{ Epolene E43 } & 22,880 & & $2.9 \%$ & & Eastman & \\
\hline & & - & $0.55,1.1,3$ and $5 \%$ & $3 / 1$ & & {$[26]$} \\
\hline Polybond PB3150 & 330,000 & - & $1.5 \%$ & $3 / 1$ and $1 / 1$ & Crompton & {$[25]$} \\
\hline Polybond PB3200 & 120,000 & & $2.5 \%$ & & Crompton & \\
\hline Epolene E43 & 9100 & & $5.8 \%$ & & Eastman & \\
\hline
\end{tabular}


one needs to be careful when assessing the results from different sources.

However, the effect of molecular weight is less clear. Most authors used low molecular weight PP oligomers to enhance the diffusion of oligomers into clay galleries [19-21,23]. However, Wang et al. [25] found that although low molecular weight $\left(M_{\mathrm{w}}=9100\right)$ oligomer resulted in better dispersion, high molecular weight $\left(M_{\mathrm{w}}=330,000\right)$ compatibilizer gave rise to better improvement in mechanical properties. In the study published by Kim et al. [26] four PP compatibilizers with varying degree of MA grafting and three PP matrix of low, medium and high viscosities were used. It was found that low viscosity PP with the compatibilizer of the lowest MA content $(0.55 \%)$ resulted in the greatest improvement of dynamic storage modulus. Without mentioning the molecular weight of compatibilizer, it is hard to judge the importance of the viscosities of individual components. Note that, regardless of the type of maleic anhydride-grafted polypropylene (PPgMA) mentioned above, the weight ratio of PPgMA to organoclay was roughly 3 in order to achieve maximum improvement in mechanical properties. As expected, too high fraction of PPgMA would be detrimental to the mechanical properties because the physical properties of compatibilizers are usually inferior to the polymer matrix; and too low fraction of PPgMA could not reach the desirable degree of clay dispersion. There would be an optimum composition for individual maleated $\mathrm{PP}$ to be incorporated into the PP/ organoclay nanocomposite.

In this study, PP is melt mixed with org-MMT and various kinds of PPgMA with broad range of MA content and molecular weight. However, an admixture of polymer and organoclay may be transformed into an exfoliated or intercalated nanocomposite or a conventional macrocomposite. The process depends critically upon the characteristics of the ingredients, such as the rheological and thermodynamic nature of the matrix polymer and compatibilizer as well as the type, packing density, and size of the organic modifier on the silicate surface. Although the underlying principles of intercalation process were well documented, most studies were conducted for direct melt compounding process under intuitive processing conditions within a limited range of MA content, and the effect of molecular weight of maleated PP is rarely discussed. In addition, it might be anticipated that melt processing conditions would have a significant impact on the nature of the nanocomposites formed. Unfortunately, until recently the literature contained no firm conclusions about the optimum conditions of the melt process. We then also examined one of the major processing parameters, i.e. the melt mixing temperature. Accordingly, this study is expected to provide fundamental information required for the successful production and application development of PP based composites, and shed some light on the interaction between the chemistry of organoclay and the processing conditions.

\section{Experimental}

\subsection{Materials}

The isotactic polypropylene homoplymer (Yungsox 1040) of injection grade provided by the Yung-Chia Chemical Co., Taiwan, was used as base polymer in this study. The density of polypropylene was $904 \mathrm{~kg} / \mathrm{m}^{3}$ measured with an electronic densimeter. Octadecylamine modified MMT clay (Nanomer ${ }^{\circledR}$ I.30 P) via ion-dipole interaction was used as the organoclay. The initial basal spacing was $2.3 \mathrm{~nm}$, and used as received from Nanocor. Four types of compatibilizers used were maleic anhydride modified polypropylenes with MA content ranging from 0.5 to $4.0 \mathrm{wt} \%$. The physical properties of the base polymer and the compatibilizers are summarized in Table 2. To all the compounds, $0.2 \mathrm{wt} \%$ heat stabilizer (EVERNOX-10) from Everspring Chemical Co., Taiwan, was added to prevent degradation of the polymer during compounding. Polypropylene and the stabilizer were dry-blended at room temperature after dehumidifying.

\subsection{Compounding procedures}

In order to seek the proper composition of compatibilizers for nanocomposites and critically compare the performance of various compatibilizers, we first employed an internal mixer, a Brabender PL 2000 plasticorder for melt compounding of the composites of clay and PPgMA compatibilizers. A mixing head of W 50 type with a mixing volume of $60 \mathrm{~cm}^{3}$ was installed. Before melt processing, all the components were dried at $80{ }^{\circ} \mathrm{C}$ for $24 \mathrm{~h}$. The organoclay, a powder with a mean particle size about $1 \mu \mathrm{m}$, and the powdered PPgMA were premixed in a tumbler. The mixing temperature was set at about the melting point of compatibilizers, rotation speed was $100 \mathrm{rpm}$, and the total mixing time was $15 \mathrm{~min}$, during which the imposed torque and temperature would reach an equilibrium value.

Table 2

Physical properties of polypropylene matrix and compatibilizers under investigation

\begin{tabular}{|c|c|c|c|c|c|}
\hline Trade name & $\begin{array}{l}\text { MI } \\
(\mathrm{g} / 10 \mathrm{~min})\end{array}$ & $\begin{array}{l}M_{\mathrm{w}} \\
(\mathrm{g} / \text { mole })\end{array}$ & $\begin{array}{l}T_{\mathrm{m}} \\
\left({ }^{\circ} \mathrm{C}\right)\end{array}$ & $\begin{array}{l}\text { MA content } \\
\text { (wt } \%)\end{array}$ & $\begin{array}{l}T_{\mathrm{d}} \\
\left({ }^{\circ} \mathrm{C}\right)\end{array}$ \\
\hline PP1040 & 2 & _- & 165 & - & 34 \\
\hline PB3150 & 20 & $330,000^{\mathrm{a}}$ & 164 & $0.5^{\mathrm{b}}$ & 335 \\
\hline PB3200 & 115 & $120,000^{\mathrm{a}}$ & 163 & $1.0^{\mathrm{b}}$ & 313 \\
\hline PB3000 & 425 & - & 161 & $1.2^{\mathrm{b}}$ & 293 \\
\hline E43 & $1654\left(180^{\circ} \mathrm{C}\right)$ & $9100^{\mathrm{b}}$ & 153 & $4.0^{\mathrm{b}}$ & 161 \\
\hline
\end{tabular}

MI: melt flow index, determined by ASTMD1238, $2.16 \mathrm{~kg}, 190^{\circ} \mathrm{C}$; $T_{\mathrm{m}}$ : melting point, determined from peak value of DSC scan; $T_{\mathrm{d}}:$ onset degradation temperature, determined from TGA analysis.

a Data obtained from literature [25].

b Manufacturer's data. 
We then prepared the PP/PPgMA/clay composites on a intermeshing, co-rotating self-wiping twin-screw extruder in the co-rotating mode. The PSM30 machine was manufactured by Sino-Alloy Machinery Inc. with a screw diameter $D$ of $31.2 \mathrm{~mm}$, the distance between screw axes was $26.2 \mathrm{~mm}$, screw tip clearance was $0.25 \mathrm{~mm}$, and the length to the diameter ratio $L / D=45$. The screw consisted of 10 segmented barrels with three kneading zones. The first kneading zone started at the second barrel consisting of high shear disk blocks, and ended with neutral blocks. The second one started at the fourth barrel also consisting of high shear elements with reverse elements at the end. The third one started at the seventh barrel with a wide-pitched low shear element. In the first and the second kneading zones, more severe shearing action is assumed due to the high shear disk blocks and due to the presence of reverse flighted elements. The reverse elements increase the resistance to flow resulting in an increase of the fill degree and the residence time in the mixing section. The wide-pitched element only induce gentle shearing and homogenization of the polymer melt $[16,17]$. Therefore, it is expected that the filler particles experience high intensity of dispersive mixing in the first and the second kneading zones; and the distributive mixing action dominates in the third kneading zone. The details of the screw configuration and element geometries are shown in Fig. 1. A standard pelletizing die plate was installed at the screw end. The strand was solidified in a water bath and pelletized.

In addition to the screw configuration, the principal processing variables were throughput rate, screw speed and barrel temperature profiles. After several trials, the screw speed was set at $200 \mathrm{rpm}$, and the barrel temperatures were set from $165^{\circ} \mathrm{C}$ at the first barrel to $180{ }^{\circ} \mathrm{C}$ at the last barrel. The barrel temperature profiles are also shown in Fig. 1. The screw speed and the barrel temperatures were fixed for all experimental runs. Besides, the throughput rate was also fixed at about $3.5 \mathrm{~kg} / \mathrm{h}$.

Furthermore, the polymer pellets, powdered PPgMA and clay were metered independently in the required proportions using volumetric dosing units. In order to achieve desirable modification of clay, the premixed organoclay and PPgMA were fed into a secondary feeding port using a forced feeder, and the PP pellets were introduced separately through the main hopper.

\subsection{Structural characterization}

Structural characterization (degree of delamination and dispersion) is carried out utilizing transmission electron microscopy (TEM) and X-ray diffraction (XRD). The TEM used in this study is a JEOL JEM-1200EX II with a $120 \mathrm{kV}$ electron accelerator. Sixty to ninety nanometer sections are prepared from the pellets via melt compounded on the twinscrew extruder. The sections, mounted on a 200 mesh copper grid, are cut using a microtome procedure with a diamond knife where the sample is held at room temperature to produce the uniform thin sections required to obtain clear reproducible images. TEM results, using an 3 by 5 in. print with a print magnification of 10,000-60,000, were categorized by counting the number of platelets or intercalates in 12 square inch cut-outs and averaging them.

The characterization of the structure by XRD is carried out on powdered samples from the pellets. The XRD instrument is a MacScience M18XHF-SRA X-ray diffractometer. The diffractometer is equipped with a $\mathrm{Cu} \mathrm{K} \alpha$ radiation source and is operated at $40 \mathrm{kV}$ and $100 \mathrm{~mA}$. The data are recorded in the reflection mode over a $2 \theta$ range of $2-10^{\circ}$ at a rate of $2 \% \mathrm{~min}$, taking measurements at equal increments of $0.02^{\circ}$.

\subsection{Rheological characterization}

The granules are compression molded using a hydraulic press and $7 \mathrm{~kg} / \mathrm{cm}^{2}$ (100 psi) of pressure and $180{ }^{\circ} \mathrm{C}$ for $20 \mathrm{~min}$. The compressed disks are $25 \mathrm{~mm}$ in diameter and $0.9 \mathrm{~mm}$ thick. The rheological characterization is carried out on a Rheometrics RDAII. A frequency range of $0.1-$ $100 \mathrm{rad} / \mathrm{s}$ and strains of $6 \%$ are applied during the measurement. A strain sweep is preformed to verify that the strain amplitude is within the linear viscoelastic regime.

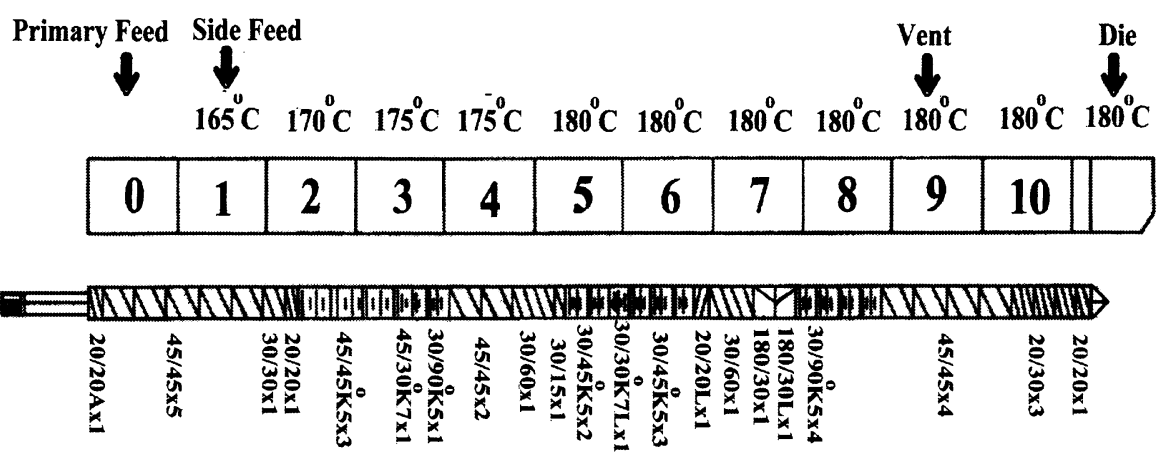

Fig. 1. Schematics of twin-screw configuration and barrel temperature profiles of PSM30. 


\subsection{Mechanical characterization}

Dynamic mechanical analyzer (DMA, Perkin Elmer 7e) is used to assess the mechanical performance of the composites. The dynamic moduli of the hybrids versus temperature are obtained by sinusoidally vibrating the samples in the three-point bending mode at $1 \mathrm{~Hz}$. The amplitude of vibration is $5 \mu \mathrm{m}$. The temperature range is between -30 and $170{ }^{\circ} \mathrm{C}$, and the heating speed is $2{ }^{\circ} \mathrm{C} / \mathrm{min}$.

\subsection{Thermal gravimetric analysis}

The thermal gravimetric analyzer (TGA, TA TGA951) is used to evaluate the thermal stability of the PP nanocomposites. The chamber was flushed with nitrogen. The temperature range is between 30 and $500{ }^{\circ} \mathrm{C}$, and the heating speed is $10^{\circ} \mathrm{C} / \mathrm{min}$.

\section{Results and discussion}

We first investigate the composites of clay and PPgMA compatibilizers prepared in the plasticorder in the hope of seeking guidelines for the suitable loading of compatibilizers in the PP/clay composites prepared on the twin-screw extruder. Therefore, the exfoliation or the intercalation behavior in PPgMA/clay composites is examined at various loadings for the four types of compatibilizers. The MA functionalized compatibilizers have been used for preparing nanocomposites in olefinic polymers such as polypropylene and polyethylene [7]. Based on the literature review, the exfoliation of layered silicates is generally enhanced by increasing the loading of PPgMA. However, there are many differences in characteristics of compatibilizers used through literature. Thus, various molecular weights and MA contents in PPgMA, and the processing parameters such as operating temperature and mixing time, have been employed. Nevertheless, the molecular weight of compatibilizer and the shear intensity for the complete exfoliation has not been clarified. In addition, the relationship between compatibilizer chemistry and the processing conditions should be coupled, since both might affect the exfoliation behavior. Thus these two factors should be considered at the same time.

\subsection{Effect of PPgMA on clay exfoliation}

Detailed experimental conditions of plasticorder are listed in Table 3 for clay composites with PB3150, PB200, PB3000, and E43, respectively. The weight ratio of PPgMA to clay was varied from 1 to 10 for investigating the degree of clay exfoliation under fixed operating conditions, where the rotation speed was $100 \mathrm{rpm}$ and the mixing time was $15 \mathrm{~min}$. The mixing temperature was determined according to the melting point of each compatibilizer. Hence the compatibilizer with high $T_{\mathrm{m}}$ and low MI was compounded at
Table 3

Experimental conditions for plasticorder (100 rpm, $15 \mathrm{~min})$

\begin{tabular}{|c|c|c|c|c|}
\hline No. & $\begin{array}{l}\text { Composition } \\
\text { (PPgMA/clay) }\end{array}$ & $\begin{array}{l}\text { Mixing } \\
\text { Temp. }\left({ }^{\circ} \mathrm{C}\right)\end{array}$ & $\begin{array}{l}\text { Equilibrium } \\
\text { Temp. }\left({ }^{\circ} \mathrm{C}\right)\end{array}$ & $\begin{array}{l}\text { Equilibrium } \\
\text { torque }(\mathrm{N} \mathrm{m})\end{array}$ \\
\hline 1 & $\mathrm{~PB} 3150 / \mathrm{I} 30=1$ & 160 & 186 & 13 \\
\hline 2 & $\mathrm{~PB} 3150 / \mathrm{I} 30=2$ & 160 & 180 & 10.2 \\
\hline 3 & $\mathrm{~PB} 3150 / \mathrm{I} 30=3$ & 160 & 178 & 9.3 \\
\hline 4 & $\mathrm{~PB} 3150 / \mathrm{I} 30=4$ & 160 & 177 & 8.6 \\
\hline 5 & $\mathrm{~PB} 3150 / \mathrm{I} 30=6$ & 160 & 176 & 7.9 \\
\hline 6 & $\mathrm{~PB} 3150 / \mathrm{I} 30=8$ & 160 & 175 & 7.1 \\
\hline 7 & $\mathrm{~PB} 3150 / \mathrm{I} 30=10$ & 160 & 174 & 6.5 \\
\hline 8 & $\mathrm{~PB} 3200 / \mathrm{I} 30=3$ & 155 & 173 & 9.7 \\
\hline 9 & $\mathrm{~PB} 3200 / \mathrm{I} 30=4$ & 155 & 169 & 7.1 \\
\hline 10 & $\mathrm{~PB} 3200 / \mathrm{I} 30=8$ & 155 & 165 & 4.8 \\
\hline 11 & $\mathrm{~PB} 3200 / \mathrm{I} 30=10$ & 155 & 164 & 4.1 \\
\hline 12 & $\mathrm{~PB} 3000 / \mathrm{I} 30=1$ & 160 & 183 & 9.4 \\
\hline 13 & $\mathrm{~PB} 3000 / \mathrm{I} 30=2$ & 160 & 177 & 6.5 \\
\hline 14 & $\mathrm{~PB} 3000 / \mathrm{I} 30=3$ & 160 & 174 & 5.8 \\
\hline 15 & $\mathrm{~PB} 3000 / \mathrm{I} 30=4$ & 160 & 171 & 4.3 \\
\hline 16 & $\mathrm{~PB} 3000 / \mathrm{I} 30=6$ & 160 & 168 & 3.8 \\
\hline 17 & $\mathrm{~PB} 3000 / \mathrm{I} 30=8$ & 160 & 166 & 1.9 \\
\hline 18 & $\mathrm{~PB} 3000 / \mathrm{I} 30=10$ & 160 & 164 & 0.9 \\
\hline 19 & $\mathrm{~PB} 3000 / \mathrm{I} 30=3$ & 150 & 167 & 8.7 \\
\hline 20 & $\mathrm{~PB} 3000 / \mathrm{I} 30=4$ & 150 & 164 & 7.3 \\
\hline 21 & $\mathrm{~PB} 3000 / \mathrm{I} 30=8$ & 150 & 161 & 5.7 \\
\hline 22 & $\mathrm{~PB} 3000 / \mathrm{I} 30=10$ & 150 & 158 & 4.9 \\
\hline 23 & $\mathrm{E} 43 / \mathrm{I} 30=1$ & 140 & 152 & 7.1 \\
\hline 24 & $\mathrm{E} 43 / \mathrm{I} 30=2$ & 140 & 146 & 3.5 \\
\hline 25 & $\mathrm{E} 43 / \mathrm{I} 30=3$ & 140 & 145 & 2.3 \\
\hline 26 & $\mathrm{E} 43 / \mathrm{I} 30=4$ & 140 & 144 & 1.4 \\
\hline 27 & $\mathrm{E} 43 / \mathrm{I} 30=6$ & 140 & 144 & 0.8 \\
\hline 28 & $\mathrm{E} 43 / \mathrm{I} 30=8$ & 140 & 144 & 0.3 \\
\hline 29 & $\mathrm{E} 43 / \mathrm{I} 30=10$ & 140 & 144 & 0.1 \\
\hline
\end{tabular}

higher temperature than that with low $T_{\mathrm{m}}$ and high MI (Table 2).

In addition, the equilibrium torque and the equilibrium temperature are also included. For effective compounding in the plasticorder, the equilibrium torque must be maintained at a certain level; therefore, the equilibrium temperature for the compatibilizer of high MI should be lower than that for the compatibilizer of low MI. Furthermore, as the ratio of PPgMA to clay increases, the torque decreases, because the shear viscosity of the composite decreases with increasing weight fraction of PPgMA. Note that, at the same weight fraction, E43/clay composites show the lowest torque among all composite systems. Particularly at high weight fractions of E43, the equilibrium torque nearly dropped to zero. Such low level of torque would lead to poor compounding of the E43/clay composites, as we shall discuss later.

We then examine the structure of composites. Fig. 2 shows the XRD patterns of the PP/I30 composite and pure I30. The (001) plane peak of the PP/I30 composite containing $5 \mathrm{wt} \%$ of I30 was observed at $2 \theta=3.49^{\circ}(2.53$ $\mathrm{nm})$, while the peak of the pure clay I30 was observed at $2 \theta=3.48^{\circ}(2.54 \mathrm{~nm})$. The observations indicate little change in the basal spacing of the clay I30 in the PP/I30 


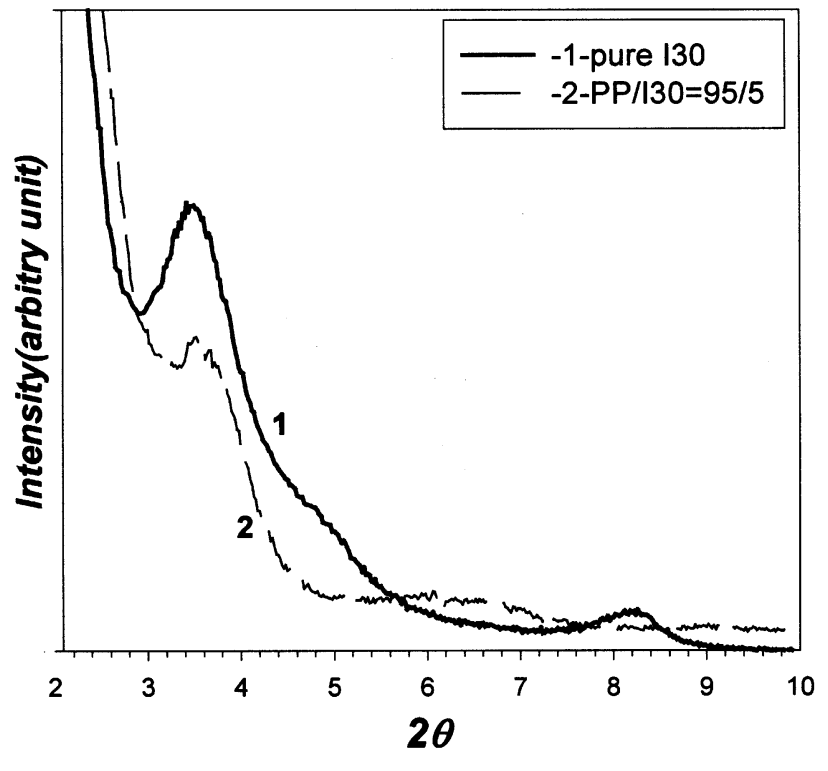

Fig. 2. XRD patterns for pure $\mathrm{I} 30$ and unmodified PP/I30 composites.

composite, which is due to the incompatibility of the polar hydroxyl groups on the surface of the clay layers and the nonpolar PP [19,23,25]. Next, we show the X-ray powder diffraction patterns for composites of I30 and compatibilizers. The results are displayed in Fig. 3(a) and (b) for PB3150/I30 and E43/I30 systems, respectively. As indicated in these XRD diffractograms, the clay characteristic peak height decreases with increasing loading of compatibilizers. While a distinct shift to lower angle is observed in Fig. 3(a) as the weight fraction of PB3150 increases, the peak is shifted to higher angles in E43/clay systems as the weight fraction of E43 increases as shown in Fig. 3(b). As mentioned above, low torque during compounding would lead to poor dispersion of clay layers in the E43 matrix, even though E43 has high MA content.

Furthermore, no more diffraction peaks are visible over the weight ratio of 4 in PB3150/I30 composites. No diffraction peak of the clay has been generally accepted as no ordered structure in the specimen exists, and it is necessary for the complete exfoliation [7]. It should be noted that there is clearly a clay characteristic peak at the weight ratio of 3 for PB3150/I30 composite even it is small. It is difficult to determine the peak location due to the peak's broadness. However, the clay characteristic peaks were only found up to 3 for PB3150/clay composites. Therefore, it can be concluded that the ordered structure of clay layers disappears in the range of weight ratio between 3 and 4 under the operating conditions, $100 \mathrm{rpm}$ and $15 \mathrm{~min}$ of mixing time.

Fig. 4(a) and (b) shows the XRD patterns of the compatibilizer/I30 composites for weight ratios of 3 and 10 , respectively. The (001) plane peak of clay I30 is shifted to the lower angles in the composites with a weight ratio of 3 , and nearly disappears in the composites with a weight ratio of 10 for all kinds of PPgMA except
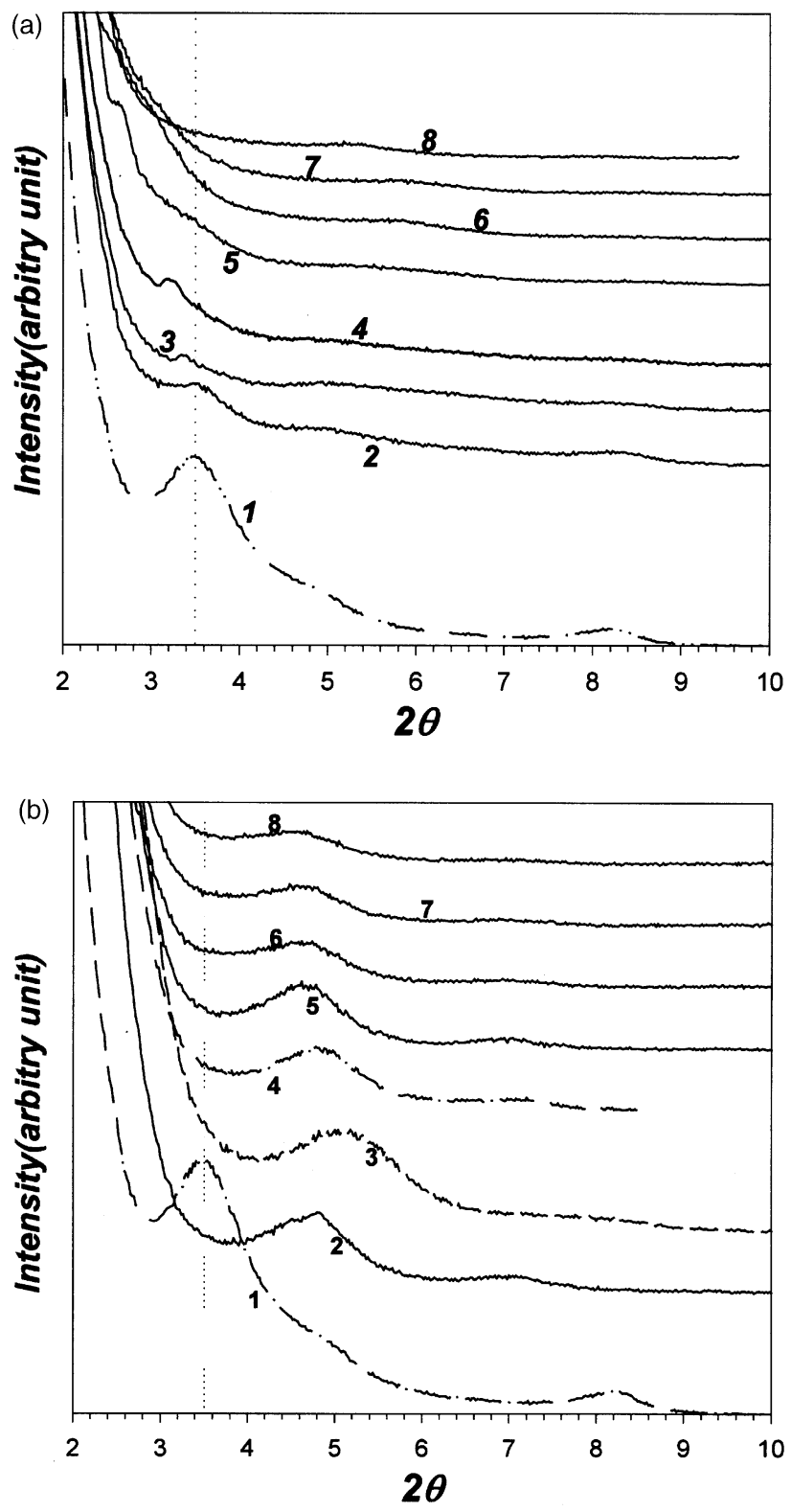

Fig. 3. XRD patterns: (a) a: pure I30, b: PB3150/I30: 1/1, c: 2/1, d: 3/1, e: 4/1, f: 6/1, g: 8/1, h: 10/1; (b) a: pure I30, b: E43/I30: 1/1, c: 2/1, d: 3/1, e: 4/1, f: $6 / 1, \mathrm{~g}: 8 / 1$, h: 10/1.

E43. As can be seen from Fig. 4(a), the peak shifting clearly indicates an intercalation structure in these composites. It also shows different peak shifting according to the molecular weight and MA content of the PPgMA compatibilizers. Disregarding E43, the biggest peak shift occurs in the PB3000/I30 composite where PB3000 has a lower $M_{\mathrm{w}}$ and a higher MA content than that of PB3150 and PB3200. Even though E43 has the lowest $M_{\mathrm{w}}$ and the highest MA content among all compatibilizers, the low MI of E43 led to low equilibrium torque (Table 3), and caused the poor dispersion of clay in the E43/I30 composites. Kinetically speaking, high polarity and mobility of E43 would enhance polymer/clay affinity and polymer chain diffusion into the clay galleries. 
However, it cannot compensate for the low equilibrium torque, which will inhibit the breakup of clay layers during compounding, and limit the intercalation of E43 into clay galleries within a short mixing period of $15 \mathrm{~min}$. Note that the low initial decomposition temperature of E43 (Table 2) may also be responsible for the poor clay dispersion. In fact, the yellowing of E43/I30 composites was clearly observed after compounding in the plasticorder.

Though the disappearance of diffraction peak under XRD scans is clearly shown in Fig. 4(b), XRD scan cannot provide definitive information on the structure of the nanocomposite, when the periodic arrangement disappears in the exfoliated clay layers. It also suffers from weak peak intensity, particularly in those composites where the clay
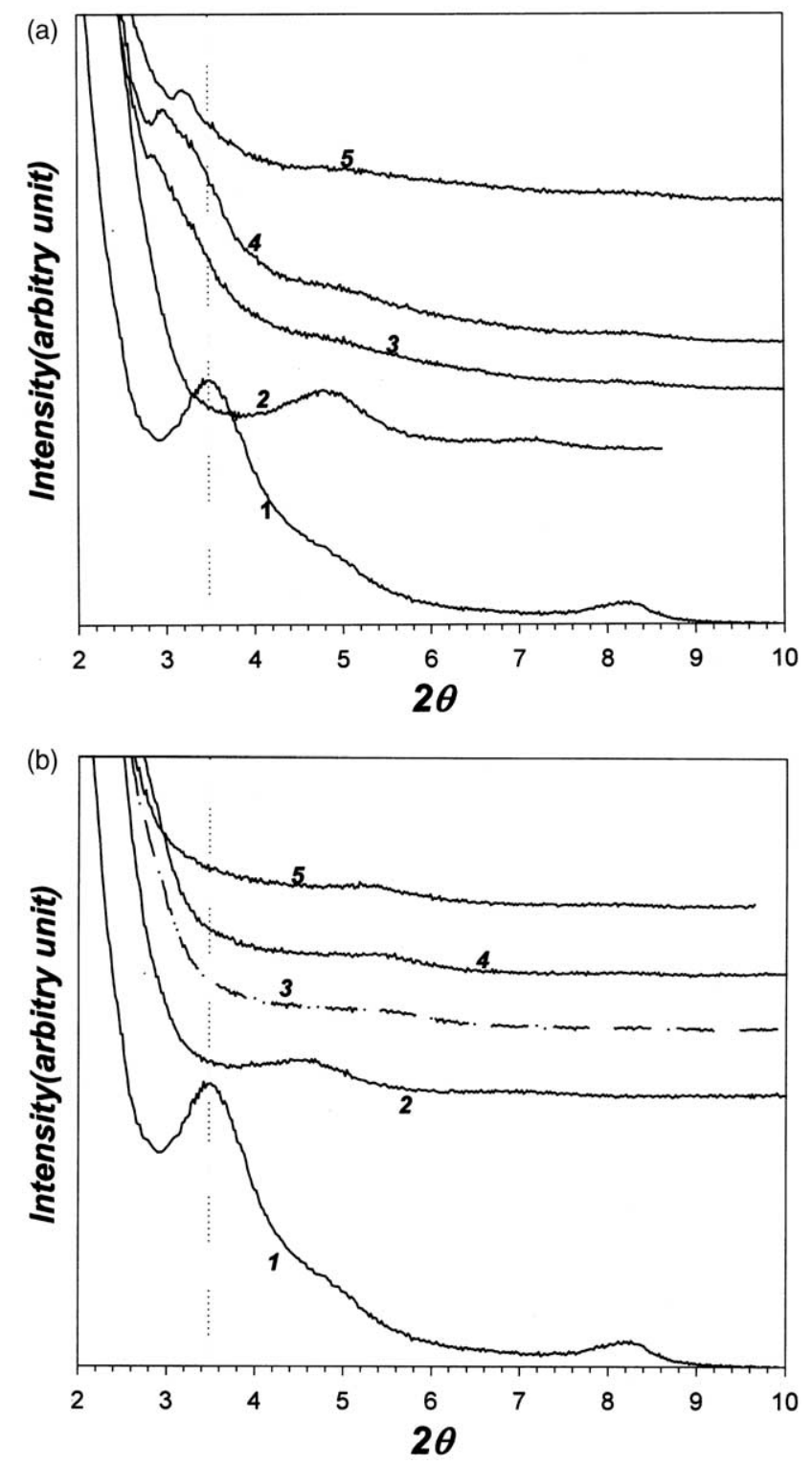

Fig. 4. (a) XRD patterns for various compatibilizer/I30 composites (a) at 3/1: a, pure I30; b, PB3150; c, PB3200; d, PB3000; e, E43 (b) at 10/1: a, pure I30; b, PB3150; c, PB3200; d, PB3000; e, E43. content is small [27]. Therefore, the TEM supplements the XRD technique by the direct observation of the state of dispersion of clay platelets in the composites.

Fig. 5(a)-(d) are TEM micrographs for PPgMA/I30 composites at the weight ratio of 10 . At the magnification of 60,000 , it can be seen that the complete exfoliation of clay platelets except the E43/I30 composites. Notice that the clay appears as the dark areas and most of the dark areas are thin lines and are well dispersed. The thin lines represent clay nanolayers within the resolution provided. Fig. 6(a)-(d) are TEM micrographs at a lower magnification of 10,000. It can be clearly seen that some clay particles are poorly dispersed as aggregates in the continuous polymer phase. The state of partial exfoliation is therefore demonstrated by the TEM observations. Fig. 7 shows the particle size distribution from TEM observations shown in Fig. 6. The long tail of E43/I30 composites indicates the poor dispersion of clay; and the largest fraction of nano-size particles in PB3000/I30 composites clearly reveals the effective exfoliation of clay layers by PB3000. However, there is not any marked difference in the clay dispersion among PB3150, PB3000, and PB3200.

Fig. 8 shows the XRD patterns of PB3000/I30 composites of weight ratios at 3 and 10 compounded at 150 and $160{ }^{\circ} \mathrm{C}$. It is interesting to see that the characteristic peak of clay shifts to lower angles for both composites. On the other hand, for composites compounded at $150{ }^{\circ} \mathrm{C}$, the peak angle is even lower than that compounded at $160^{\circ} \mathrm{C}$. This again demonstrates the importance of delamination under shear during melt compounding. High temperature enhances bulk diffusion [12], but lowers shear viscosity. Similar to the situation of E43, low viscosity at high mixing temperature will not generate enough shear for breaking up the clay layers, and will lead to poor dispersion of clay.

The two morphologies that show the shifting to different angles of clay diffraction peaks are compared in Figs. 6(c) and 9, respectively. The weight ratio is 10 in order to unambiguously observe the dispersion state of clay. As indicated in literature, these two figures show two typical morphologies of the polymer/clay mixture, i.e. exfoliated and unexfoliated clay dispersion, respectively. Thus, it can be seen that a large number of stacked clay platelets are shown in Fig. 9 for composites compounded at $160{ }^{\circ} \mathrm{C}$, however, the exfoliated individual platelets are well dispersed throughout the matrix in Fig. 6(c) for composites at $150{ }^{\circ} \mathrm{C}$ except few aggregates. It then can be deduced that the smaller shifting of clay diffraction peaks in Fig. 8 indicates a more inhomogeneous partially exfoliated morphology in this experimental system.

\subsection{Effect of PPgMA on the dispersion and properties of $P P /$ clay composites}

From previous discussion, it is found that the intercalation power of compatibilizers could be realized at a weight ratio of roughly 3 , regardless of differences in the 


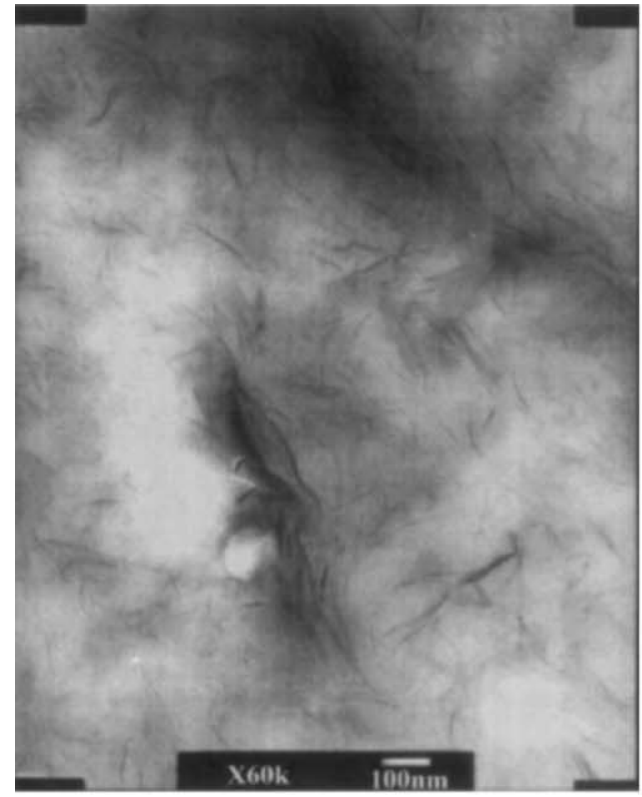

(a)

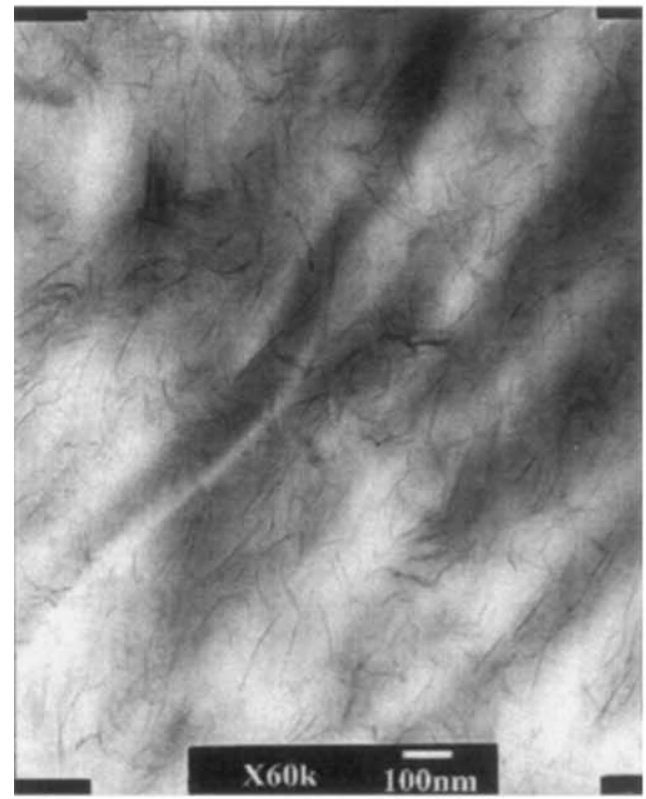

(c)

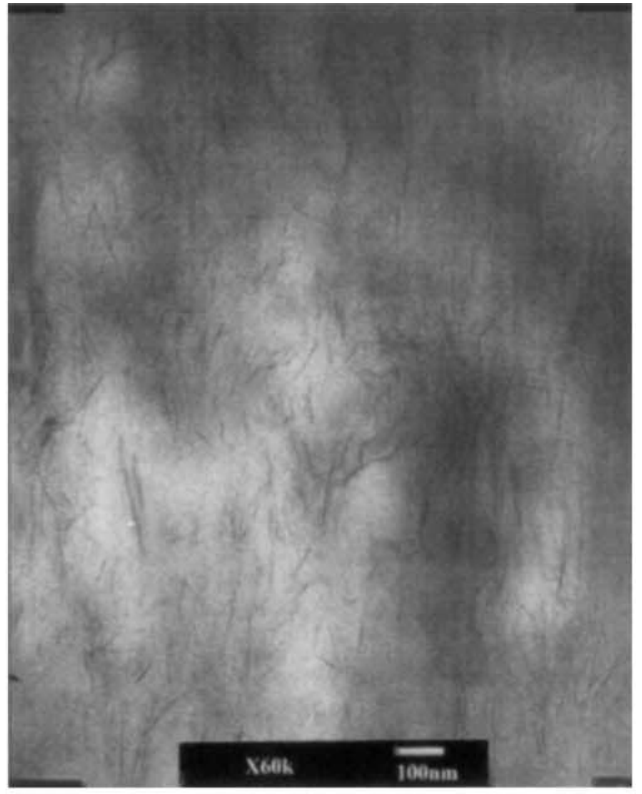

(b)

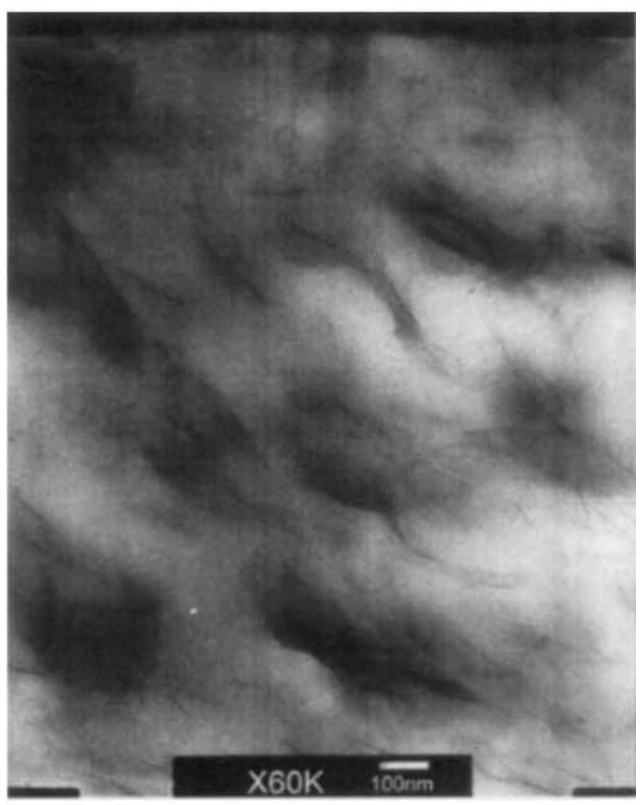

(d)

Fig. 5. (a)-(d) TEM micrographs $(\times 60,000)$ of PB3150, PB3200, PB3000, E43/I30 composites at 10/1.

compatibilizers. Therefore we shall use weight ratios around that value in the following formulations for modifying PP/I30 composites. Direct evidence of the intercalation is provided by the XRD patterns of the obtained hybrids. Fig. 10 shows the XRD patterns of PP/I30 composites modified with PB3150, PB3000, and E43 at the weight ratio of $80 / 15 / 5$ from the twin-screw extruder. It does not show any significant difference from those of compatibilizer/I30 composites, i.e. the characteristic peak of I30 is shifted to lower angles in all samples except E43/I30 composites. This clearly indicates the intercalation of polymer chains between silicate layers. In addition, the XRD patterns exhibit relatively small and unapparent peaks or shoulders with a gradual increase in the diffraction strength toward low angles. Completely dispersed composites exhibit no peak but a gradual increase in the diffraction strength $[7,19]$. Therefore, the clay layers in the composites should be well exfoliated and dispersed.

In order to confirm the exfoliated structure, the dispersibility of the silicate layers was also observed by TEM. Fig. 11(a)-(c) shows the TEM micrographs at high magnification of 60,000 of compatibilizer modified PP/I30 


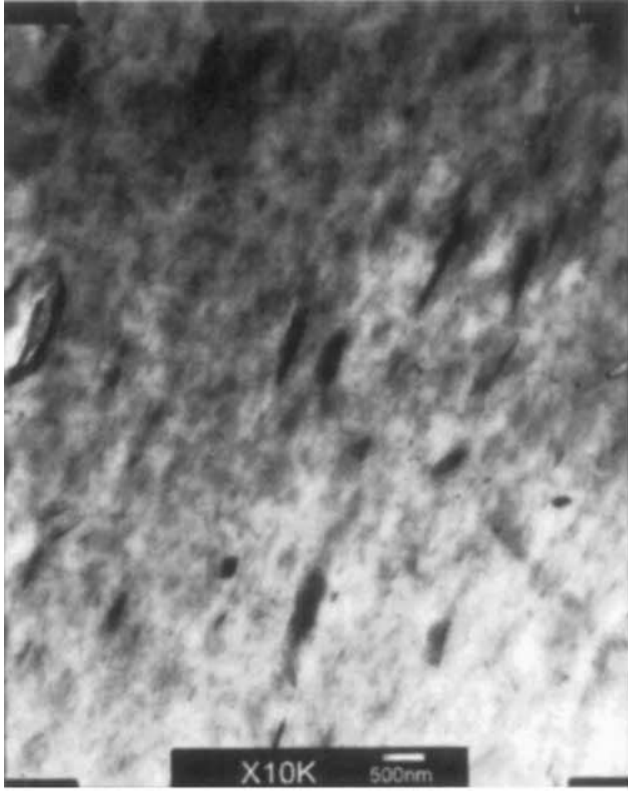

(a)

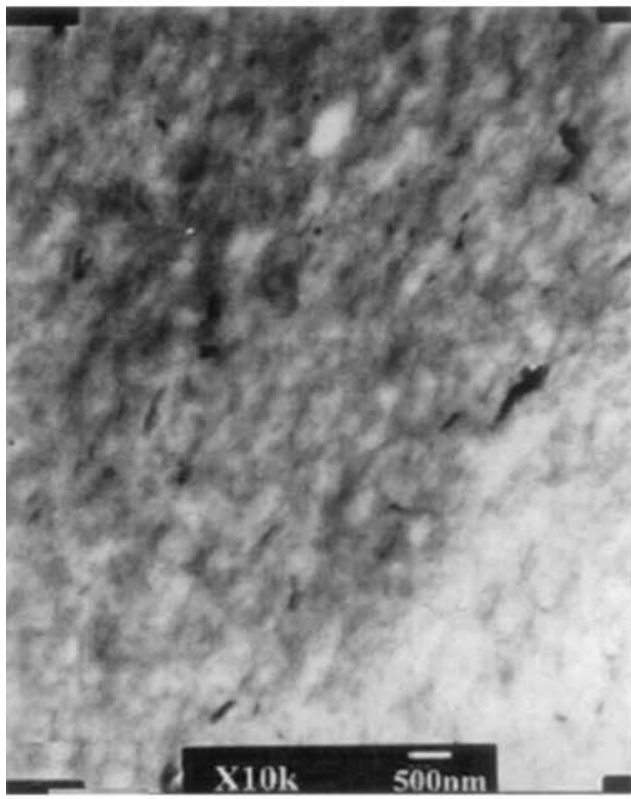

(c)

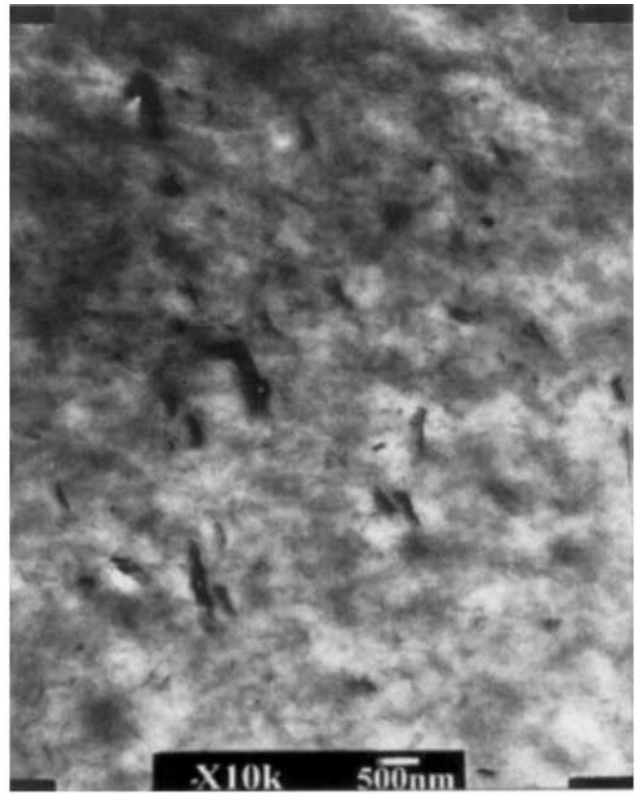

(b)

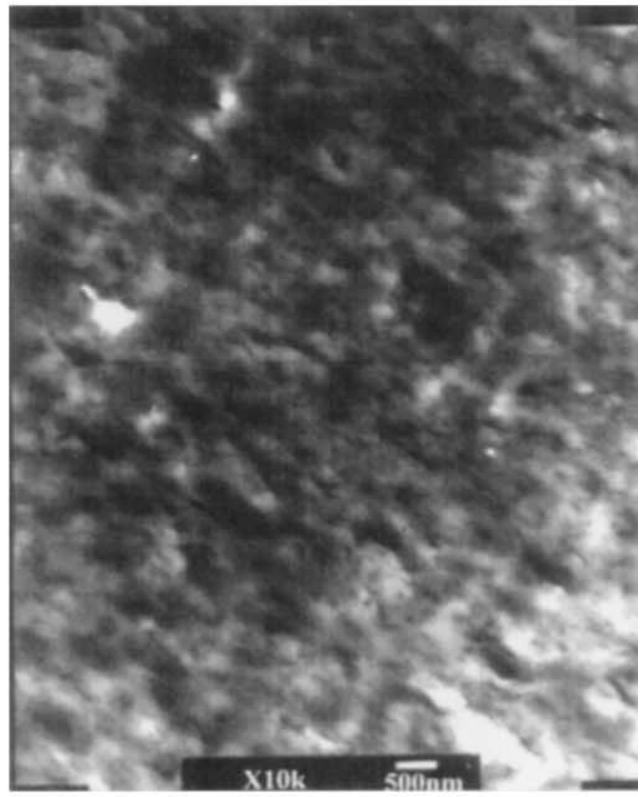

(d)

Fig. 6. (a)-(d) TEM micrographs $(\times 10,000)$ of PB3150, PB3200, PB3000, E43/I30 composites at 10/1.

composites. In Fig. 11(a) and (b) for PB3150 and PB3000 modified composites, the gray lines are the intersections of the silicate layers of $1 \mathrm{~nm}$ thickness. Each layer of the clay is dispersed homogeneously in the PP matrix, although a slight amount of intercalated layers (but unexfoliated) still exists. The existence of small peaks in the XRD patterns should be attributed to these intercalated layers. On the other hand, the dark areas indicate that the clay platelets are poorly dispersed as aggregates in the continuous PP phase in the E43 modified system (Fig. 11(c)). During the evolution of phase structure after the incorporation of the compatibilizer, an extra contribution arises from the specific interaction derived by hydrogen bonding between silicate layer and MA group. Such interaction is no doubt beneficial to overcoming the energy barrier to form randomized delamination of silicate layers, i.e. exfoliated structure. However, it is possible to reduce the miscibility with the PP matrix due to a too high MA content [19]. Fortunately, within the available range of MA content employed in this study, we did not observe any problem of immiscibility between compatibilizer and PP matrix.

Besides the local technique of XRD and TEM, the rheological characterization is also a sensitive method to reveal the global state of dispersion in the composites [28, 


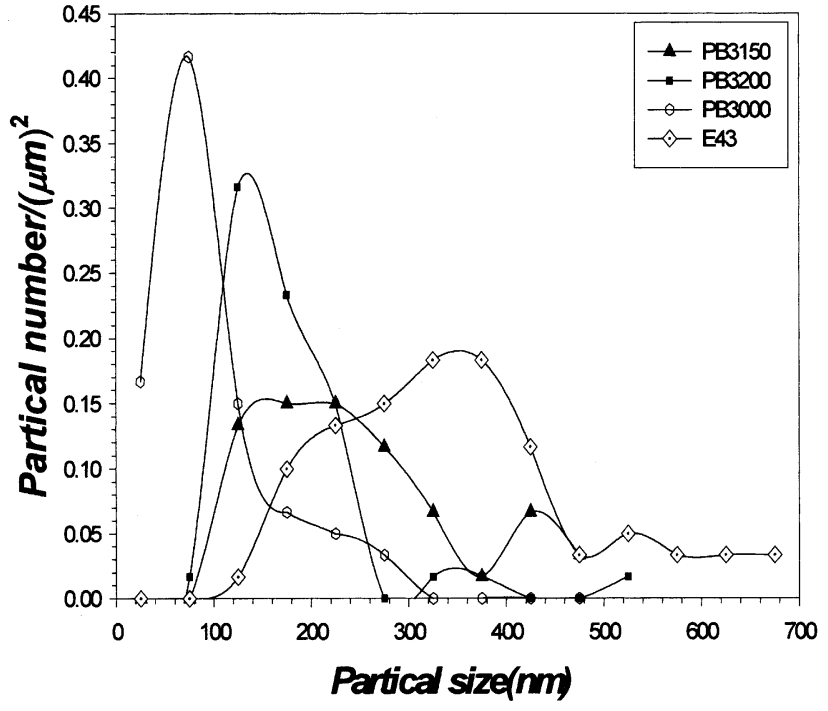

Fig. 7. Particle size distribution from TEM observations for various compatibilizers at $10 / 1$.

29]. The melt viscosity of these hybrid polymer nanocomposites is related to the aspect ratio of individual fillers. The aspect ratio of the filler is then related to the intercalation of the clay. Therefore, the aspect ratio is changing according to different levels of intercalation. The magnitude of the complex viscosity, $\left|\eta^{*}\right|$, of the composites divided by the complex viscosity of the matrix (either neat PP or PP/ compatibilizer) is the relative viscosity. Fig. 12(a) presents the relative viscosity of the composites to neat PP. It can be seen that, on one hand, PP/PB3150/I30 composite shows the greatest enhancement in the dynamic viscosity mainly due to the low MI of PB3150. On the other hand, the dynamic viscosity of $\mathrm{PP} / \mathrm{E} 43 / \mathrm{I} 30$ composite is even lower than that of neat PP. Besides the high MI of E43, the poor dispersion of clay platelets in the composite may also contribute to such

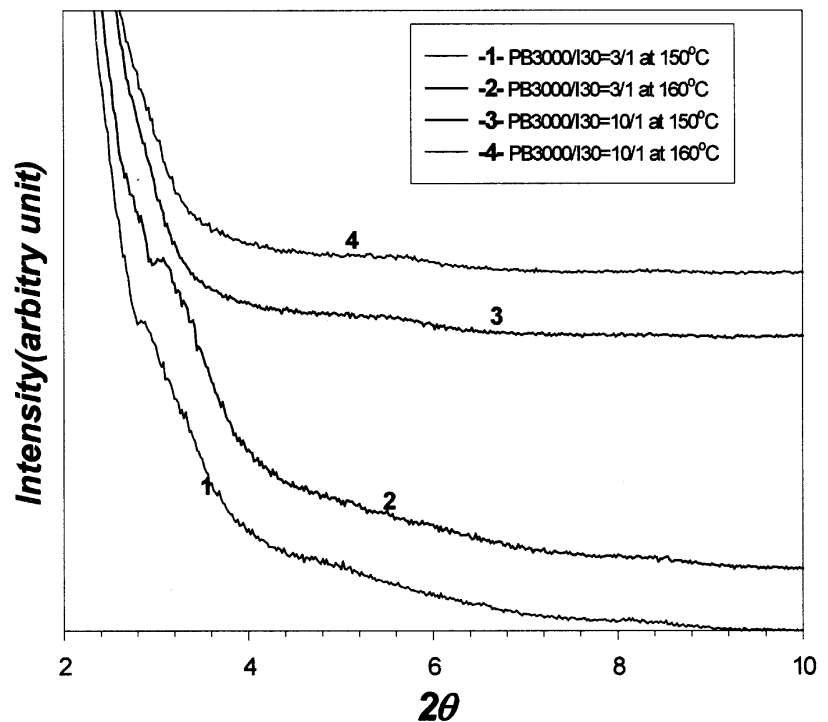

Fig. 8. XRD patterns for PB3000/I30 composites compounded at 150 and $160{ }^{\circ} \mathrm{C}$.

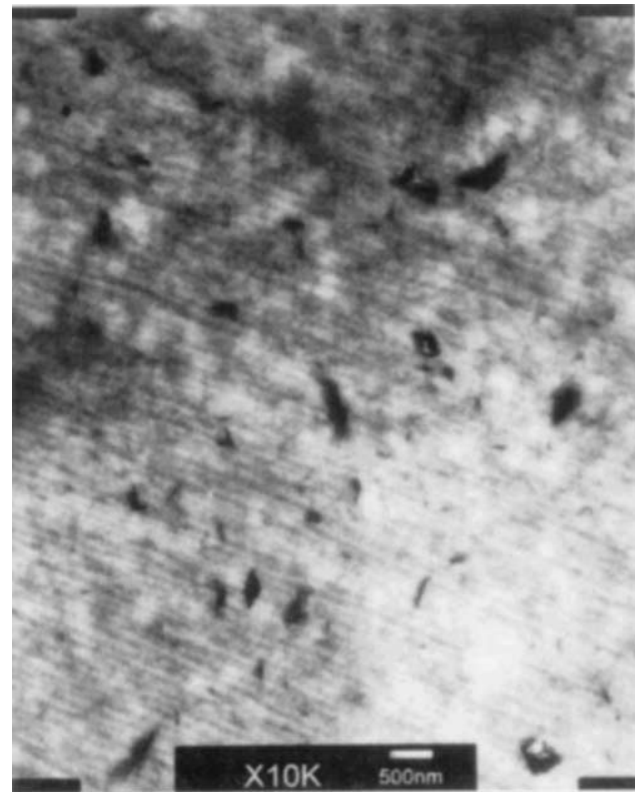

Fig. 9. TEM micrograph $(\times 10,000)$ of PB3000/I30 composites compounded at $160^{\circ} \mathrm{C}$.

low level of complex viscosity. Furthermore, the enhancement of complex viscosity is most significant in the low frequency region for both composites modified by PB3150 and PB3000, which may suggest a change form liquid-like to solid-like behavior at low frequencies [30]. In order to isolate the effects of the fillers on the composite viscosity, Fig. 12(b) presents the relative viscosity curves of three nanocomposites modified by different compatibilizer to the corresponding $\mathrm{PP} /$ compatibilizer matrix. As expected, we notice that the PP/E43/I30 composite exhibits the least enhancement in the relative viscosity. However, contrary to the results shown in Fig. 12(a), PP/PB3000/I30 composite

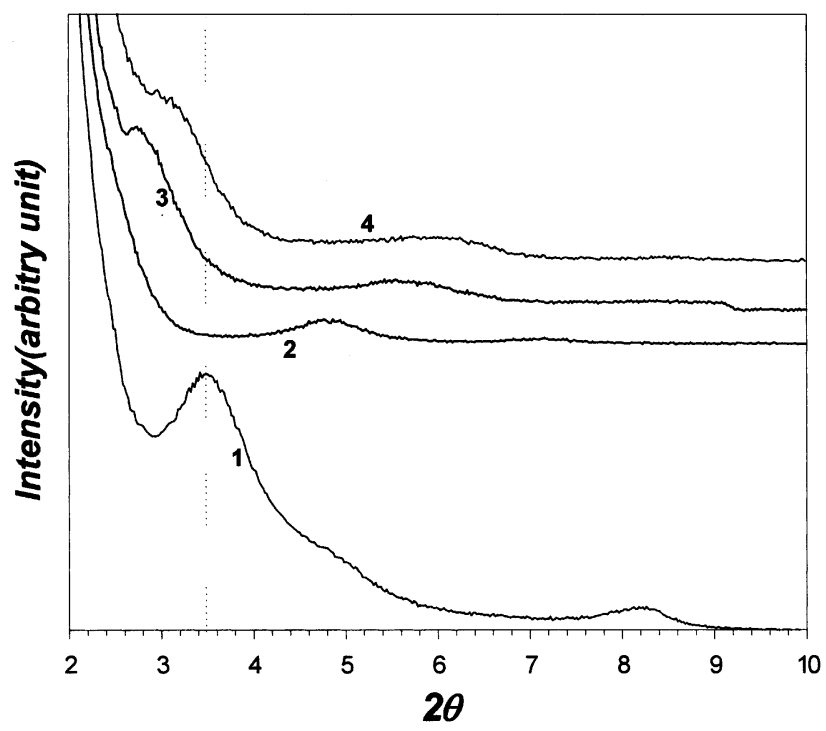

Fig. 10. XRD for compatibilizers modified PP/I30 composites. (a) PP/PB3150/I30 at 80/15/5; (b) PP/PB3000/I30 at 80/15/5; (c) PP/E43/I30 at $80 / 15 / 5$. 


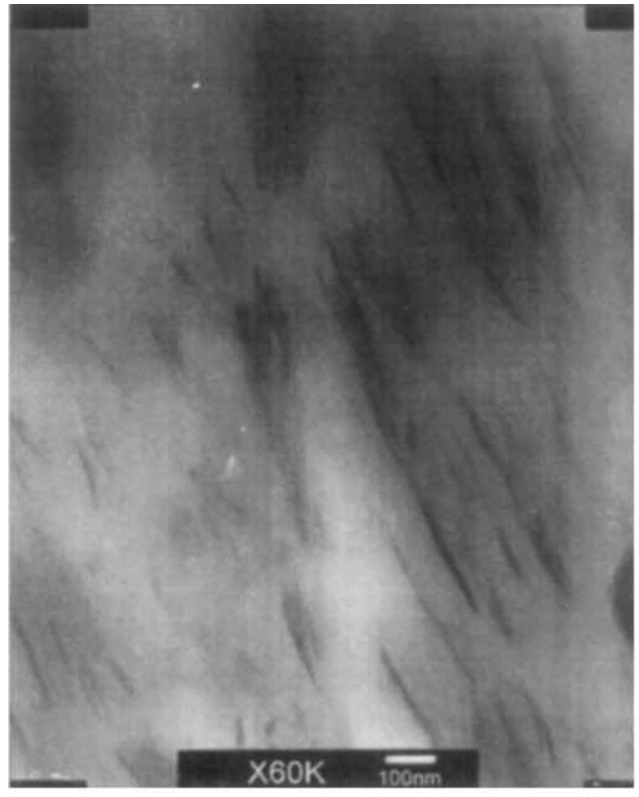

(a)

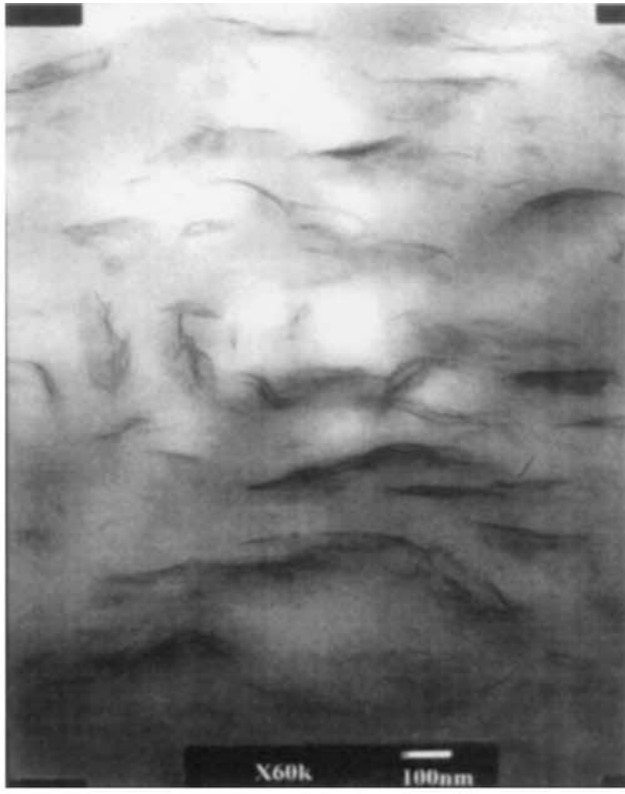

(b)

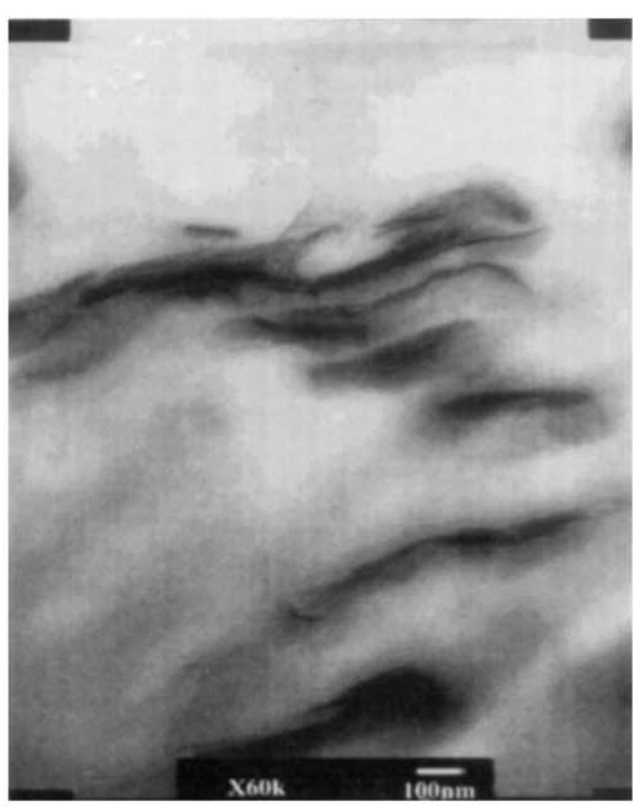

(c)

Fig. 11. (a) $-($ c $)$ TEM micrographs $(\times 60,000)$ for compatibilizers modified PP/I30 composites.

shows greater enhancement than PP/PB3150/I30 composites, though a similar trend is displayed in Fig. 12(b) for the two composites. We think it represents a more homogeneous dispersion of clay platelets in the PP/PB3000/I30 system. Referring to the XRD patterns and the TEM micrographs, such a procedure may be used to arrive at a representation of the global nanostructure from the relative viscosity curve for a hybrid structure. We shall pursue this subject further in the future study.

The dynamic storage moduli $\mathrm{E}^{\prime}$ of modified PP/I30 composites are plotted versus temperature in Fig. 13. Note that the composition corresponding to the maximum improvement for each compatibilizer is different. The composition for $\mathrm{PP} / \mathrm{PB} 3150 / \mathrm{I} 30$ composites is $80 / 15 / 5$; however, the composition is $85 / 10 / 5$ for PP/PB3000/I30, and 90/5/5 for PP/E43/I30 systems. We adopted different loadings for individual compatibilizers because a balance between the compatibilizer stiffness and the loading is required to achieve maximum improvement of composite properties [21,25]. It can be seen that all the modified PP/I30 composites exhibit similar moduli curves versus temperature. The moduli of the PP/PB3150/I30 system show 

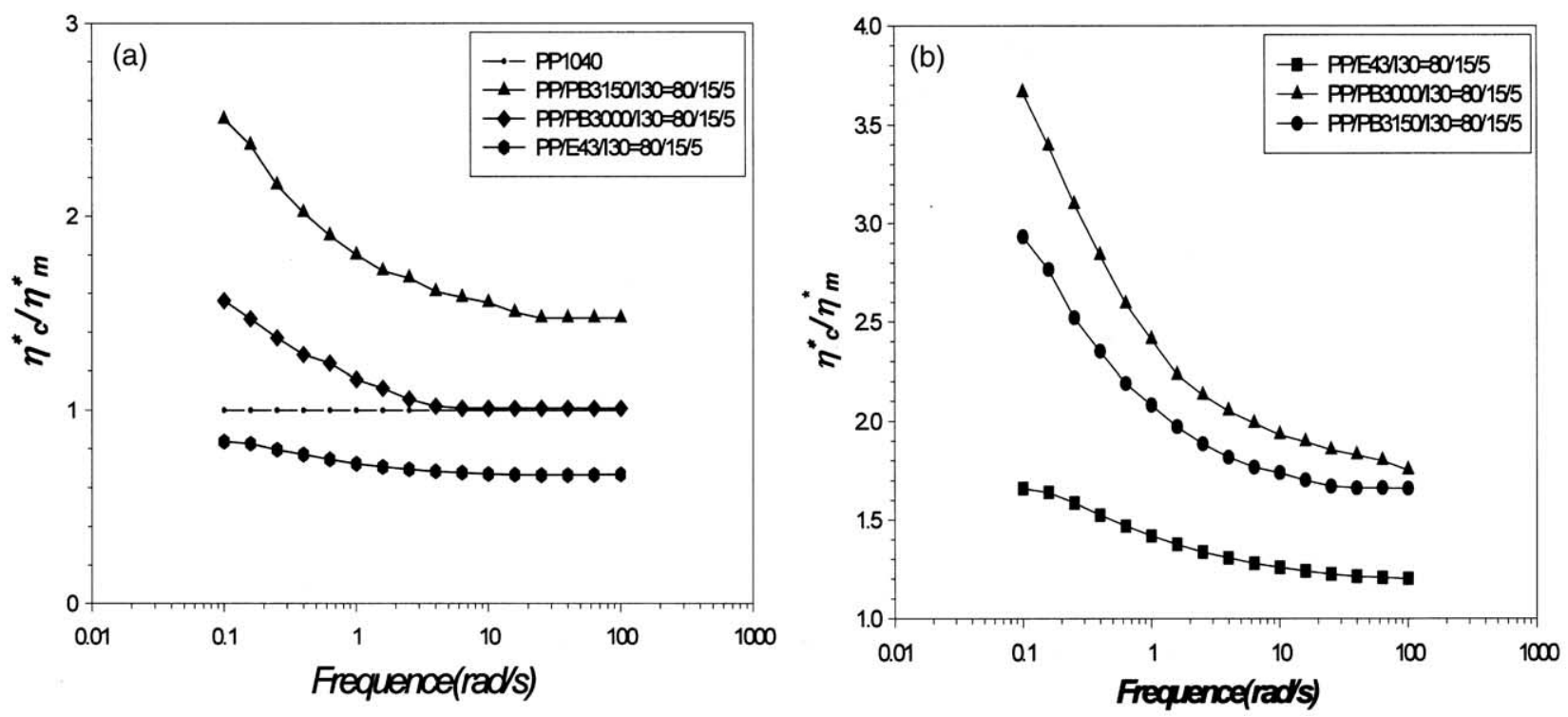

Fig. 12. The relative dynamic viscosity of compatibilizer modified composites to (a) neat PP and (b) PP/PPgMA.

the greatest improvement among all composite systems. The relative storage moduli of modified PP/I30 composites to pristine PP is plotted in Fig. 14. It clearly shows the dependence of the $\mathrm{E}^{\prime}$ of the modified PP/I30 composites on the kind of compatibilizers. In particular, the PP/PB3150/ I30 system exhibits nearly 1.6 times higher modulus than that of the pristine PP at $70{ }^{\circ} \mathrm{C}$ by using only $5 \%$ of clay. This is most likely due to the fact that the softening point of PB3150 is the highest among all compatibilizers. Another reason may be the improved dispersibility of clay layers by adding the compatibilizer. Apparently, the relative moduli of the clay composites are higher than unity over the whole

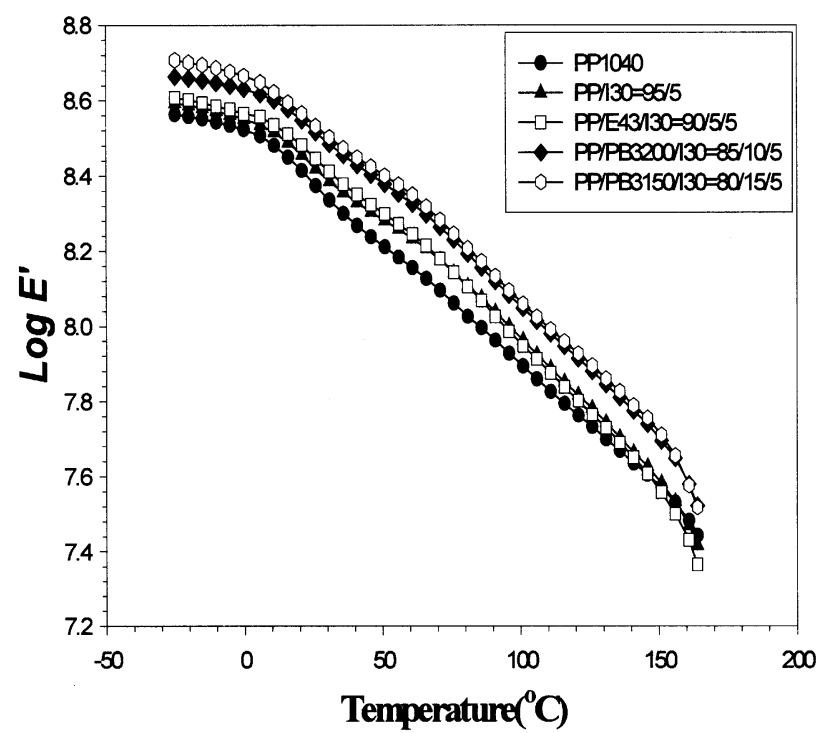

Fig. 13. DMA scans of pure PP and compatibilizer modified PP/I30 composites. temperature range, and these are considered to be the real reinforcement effect of clays. As expected, the PP/E43/I30 composites exhibit the least enhancement.

The thermal decomposition behavior of pristine PP and compatibilizers modified PP/I30 composites are shown in Fig. 15. The onset degradation temperatures of the nanocomposites vary from $205^{\circ} \mathrm{C}$ for $\mathrm{E} 43$ modified composite to $374{ }^{\circ} \mathrm{C}$ for $\mathrm{PB} 3150$ modified composite. The onset degradation temperature of unmodified PP/I30 composites is $347^{\circ} \mathrm{C}$, which is higher than that of E43 modified composite. The improvement in thermal stability, except E43 modified system, may be resulted from the

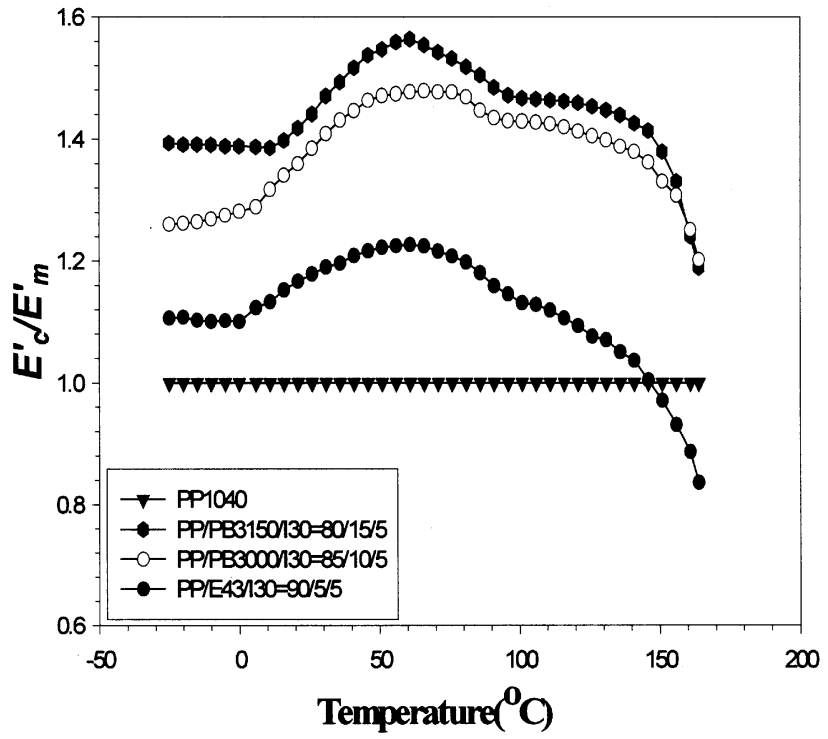

Fig. 14. The relative dynamic modulus of compatibilizer modified PP/I30 composites to neat $\mathrm{PP}$. 


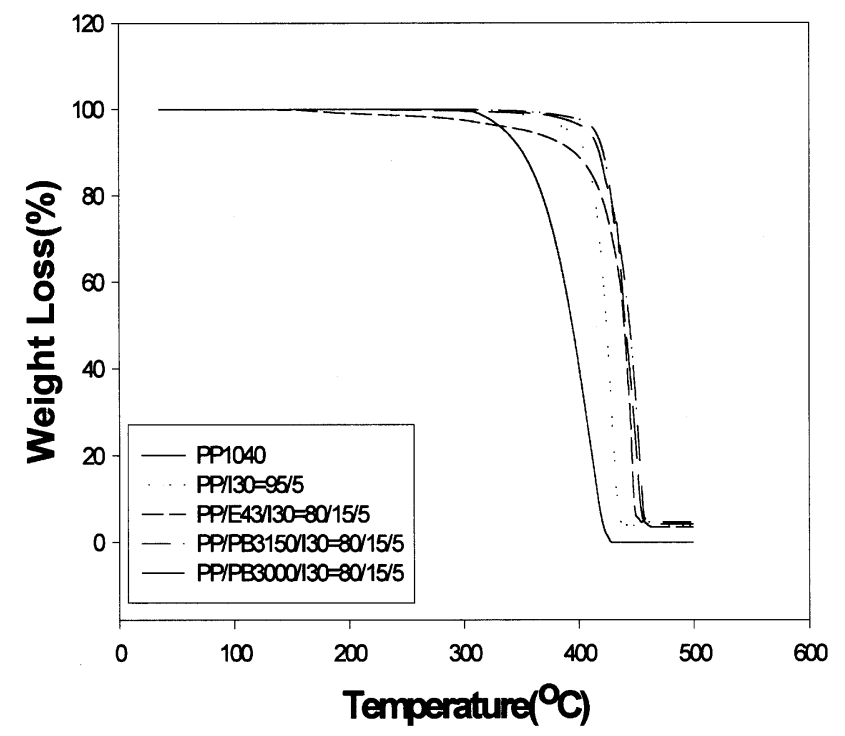

Fig. 15. TGA thermograms of weight loss versus temperature for compatibilizer modified PP/I30 composites.

interaction between organic and inorganic phases. Individual layers of exfoliated clay platelets act as insulator, and the formation of tortuous path between layers also inhibits the passage of volatile degradation products, hence enhances the thermal stability of clay composites.

\section{Conclusions}

During melt compounding of PPgMA compatibilizers and organoclay, the intercalation capability of PPgMA had been well known due to the polarity in the MA moiety. In addition to the polarity, the molecular weight, which determined the shear viscosity of PPgMA, also played a vital role in the effective breakup of clay agglomerates, especially when the organoclay was capable of compensating the entropy loss of confined polymer chains by improving the chemical affinity with PPgMA. Regardless of various types of compatibilizers, all PPgMAs gave rise to similar degree of dispersion over the weight ratio of 3 to 1 with the exception of E43. It was found that thermal instability and high melt index were responsible for E43's ineffectiveness. As a result, the relationship between the chemistry of compatibilizers and the processing conditions should be coupled, since both might affect the exfoliation behavior. Therefore, PPgMA with low melting point and high melt index was compounded at low equilibrium temperature in order to maintain a high level of shear viscosity and provide reasonable torque in the plasticorder.

Upon the addition of PPgMA for modifying the PP/clay mixtures, a series of composite materials based on various combination of PP, PPgMA, and organoclay were melt compounded in a twin-screw extruder. The composites were analyzed to understand the major factors that affect the final morphology and mechanical property of the composites. It was found there were two important factors that helped the exfoliation and homogeneous dispersion of the clay layers: (1) the intercalation capability of the compatibilizers in the clay layers; and (2) the composition of the compatibilizer in the PP/clay composites. Almost complete hybrids were obtained in the case where the PPgMA has the intercalation capability with a PPgMA/clay weight ratio over 3 to 1 . Rheological characterization by complex viscosity also demonstrated that PPgMA of low molecular weight and high MA content led to better interaction with clay. However, the addition of lower molecular weight PPgMA or high loading of PPgMA had a negative effect on mechanical and thermal properties of the PP/PPgMA/clay composites.

\section{Acknowledgements}

The authors thank the Union Chemical Laboratories of the Industrial Technology Research Institute for their financial support. We are also grateful to the Instruments Center at the National Chung Hsing University for helping with the TEM images.

\section{References}

[1] Brandmaier HE. In: Milewski JV, Katz HS, editors. Handbook of reinforcements for plastics. New York: Van Nostrand Reinhold; 1987. p. 6-13 [chapter 2].

[2] Gibson AG. In: Karger-Kocsis J, editor. Polypropylene: structure, blends and composites, vol. 3. London: Chapman \& Hall; 1995. p. 71-112 [chapter 2].

[3] Kojima Y, Usuki A, Kawasumi M, Okada A, Kurauchi T, Kamigaito J. J Polym Sci, Part A: Polym Chem 1993;31:983-6.

[4] Giannelis EP. Adv Mater 1996;8(1):29-35.

[5] Lau KT, David H. Composites: Part B 2002;33:263-77.

[6] Pinnavaia TJ, Lan T, Wang Z, Shi H, Kaviratna PD. In: Chow GM, Gonsalves KE, editors. Nanotechnology. ACS Symposium Series, vol. 622; 1996. p. 251.

[7] Zilg C, Reichert P, Dietsche F, Engelhardt T, Mülhaupt R. Kunststoffe 1998;88:1812.

[8] Alexandre M, Dubois P. Mater Sci Engng 2000;28:1-63.

[9] Pinnavaia TJ, Beall GW, editors. Polymer clay nanocomposites. New York: Wiley; 2000.

[10] Vaia RA, Ishii H, Giannelis EP. Chem Mater 1993;5:1694-6.

[11] Vaia RA, Vasudevan S, Krawiec W, Scanlon LG, Giannelis EP. Adv Mater 1995;7:154-6.

[12] Vaia RA, Jandt KD, Kramer EJ, Giannelis EP. Macromolecules 1995; 28:8080-5.

[13] Vaia RA, Jandt KD, Kramer EJ, Giannelis EP. Chem Mater 1996;8: $2628-35$.

[14] Vaia RA, Giannelis EP. Macromolecules 1997;30:8000-9.

[15] Liu L, Qi Z, Zhu X. J Appl Polym Sci 1999;71:1133-8.

[16] Cho JW, Paul DR. Polymer 2001;42:1083-94.

[17] Dennis HR, Hunter DL, Chang D, Kim S, White JL, Cho JW, Paul DR. Polymer 2001;42:9513-22. 
[18] Kurokawa Y, Yasuda H, Kashiwagi M, Oya A. J Mater Sci Lett 1997; 16:1670-2.

[19] Kawasumi M, Hasegawa N, Kato M, Usuki A, Okada A. Macromolecules 1997;30:6333-8.

[20] Kato M, Usuki A, Okada A. J Appl Polym Sci 1997;66:1781-5.

[21] Hasegawa N, Kawasumi M, Kato M, Usuki A, Okada A. J Appl Polym Sci 1998;67:87-92.

[22] Oya A, Kurokawa Y, Yasuda H. J Mater Sci 2000;35:1045-50.

[23] Reichert P, Nitz H, Klinke S, Brandsch R, Thomann R, Mülhaupt R. Macromol Mater Engng 2000;275:8-17.

[24] Ishida H, Campbell S, Blackwell J. Chem Mater 2000;12: 1260-7.
[25] Wang H, Zeng C, Svoboda P, James Lee L. Preparation and properties of polypropylene nanocomposites. 59th ANTEC Proceedings, Dallas; 2001. p. 2203-7.

[26] Kim K-N, Kim H-S, Lee J-W, 58th ANTEC Proceedings, New York; 2000. p. 3782-6.

[27] Galgali G, Ramesh G, Lele A. Macromolecules 2001;34:852-8.

[28] Krishnamoorti R, Giannelis E. Macromolecules 1997;30: 4097-102.

[29] Solomon MJ, Almusallam AS, Seefeldt KF, Somwangthanaroj A, Varadan P. Macromolecules 2001;34:1864-72.

[30] Ren J, Silva AS, Krishnamoorti R. Macromolecules 2000;33: 3379-746. 